DOI: https://doi.org/10.31933/jemsi.v2i5

Received: 16 April 2021, Revised: 25 Mei 2021, Publish: 4 Juli 2021

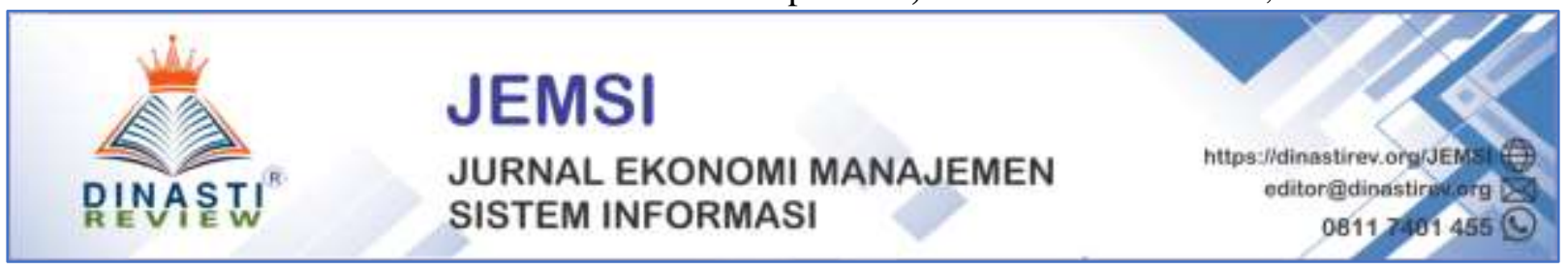

\title{
FAKTOR INTERNAL DAN FAKTOR EKSTERNALTERHADAP KINERJA GURU DI MASA PANDEMI COVID-19
}

\section{Yuyun Kamijan}

Mahasiswa Program Manajemen Sumber Daya Manusia (SDM), Universitas Mercu Buana, yuyunkamijan1209@gmail.com

\begin{abstract}
Abstrak: Lingkungan kerja adalah segala sesuatu yang ada disekitar para pegawai yang dapat mempengaruhinya dalam menjalankan tugas-tugas yang di berikan. Lingkungan kerja dapat menciptakan hubungan kerja yang mengikat antara orang-orang yang ada di dalamnya. Lingkungan kerja dalam suatu organisasi mempunyai arti penting bagi individu yang bekerja di dalamnya, karena lingkungan akan mempengaruhi kepuasan individu dalam bekerja. Adapun tujuan artikel ini untuk mengetahui lingkungan internal dan eksternal serta factor- fakror apa sajakah yang mempengaruhi kinerja guru pada saat pandemi covid-19. Hasil artikel literatur review ini adalah: 1. Faktor internal ; 2. Faktor eksternal ;3. Hal yang mempengaruhi kinerja guru dimasa pandemi covid-19.
\end{abstract}

Kata kunci: Faktor internal, Faktor eksternal, kinerja guru, covid-19

\section{PENDAHULUAN}

\section{Latar Belakang Masalah.}

Wabah Pandemi Covid-19, merupakan bencana internasional yang mengguncang segala aspek kehidupan, termasuk dunia pendidikan. Dengan adanya wabah tersebut, otomatis tidak ada pertemuan tatap muka untuk menghindari penyebaran covid-19, atau setidaknya diminimalisirnya pertemuan, diantaranya pertemuan guru dengan murid. Proses KBM mulanya diliburkan, tetapi seiring berjalannya waktu, sembari menunggu vaksin covid-19 rilis, diberlakukanlah new normal. 
KBM harus tetap berjalan dengan memaksimalkan teknologi yang mendukung pembelajaran jarak jauh.

Menurut data yang dikeluarkan oleh UNISCO bahwa kualitas guru Indonesia sebagai komponen kunci dalam Pendidikan berada di urutan terakhir, yaitu urutan ke-14 dari 14 negara berkembang di dunia. satu hal ini tentu perlu menjadi perhatian karena guru merupakan kunci sukses pendidikan yang ada di sekolah. Munadi dalam Rusman (2017, hlm. 130) ada dua macam faktor akibat timbulnya kesulitan dalam proses belajar mengajar yang mempengaruhinya antara lain:

\section{Faktor Internal}

facrudin (2000:52) menerangkan bahwa faktor internal adalah factor yang berasal dari dalam diri seseorang yang dapat mempengaruhi kinerja seseorang dalam menjalankan pekerjaannya,. Faktor kesulitan dalam pengajaran juga berpengaruh pada prestasi belajarnya, selain itu juga dapat dibuktikan dengan munculnya kelainan perilaku siswa akibat pandemi ini, seperti: tidak adanya keinginan untuk belajar secara mandiri. faktor akibat timbulnya kesulitan yang mempengaruhi hasil belajar antara lain:
a. Faktor Fisiologis
b. Faktor Psikologis
c. Psiko motor

2. Faktor Eksternal

faktor eksternal yaitu faktor yang datang dari luar diri yang dapat mempengeruhi kinerjanya, antara lain lingkungan fisik, sarana dan prasarana, imbalan, suasana, kebijakan dan sistem administrasi. Dengan demikian dapat mempengaruhi dipahami bahwa, dorongan motivasi dari dalam diri seorang guru memiliki peran besar terhadap pencapaian tujuan peningkatan mutu peserta didik.

Kinerja guru adalah hasil kerja yang dapat dicapai oleh seorang guru di lembaga pendidikan atau madrasah sesuai dengan tugas dan tanggung jawab dalam mencapai tujuan pendidikan (Asf \& Mustofa, 2013:155-156). Keberhasilan seorang guru harus memenuhi kriteria yang telah ditetapkan, apabila guru telah memenuhi kriteria tersebut berarti seorang guru dapat dikatakan berhasil dan memiliki kualitas yang baik. Sebaliknya apabila seorang guru belum memenuhi kriteria yang baik maka guru belum dapat dikatakan berhasil. 
Faktor-faktor yang memengaruhi kinerja guru seseorang dapat berasal dari dalam individu itu sendiri seperti motivasi, keterampilan, dan juga pendidikan. Ada juga faktor dari luar individu seperti iklim kerja, tingkat gaji, dan lain sebagainya (Asf \& Mustofa, 2013:160)

Faktor-faktor lingkungan yang dapat memengaruhi kinerja guru banyak, tiga di antaranya sebagai berikut:

1. Kepemimpinan Kepala Sekolah Kepemimpinan kepala sekolah adalah usaha seorang individu yang dipercaya sebagai seorang pemimpin organisasi di sekolah yang memengaruhi anggotanya meliputi guru, staf/karyawan, murid, dan komite sekolah untuk mewujudkan suatu tujuan pendidikan.

2. Motivasi Kepala Sekolah Motivasi kepala sekolah adalah suatu dorongan yang diberikan kepala sekolah terhadap guru agar lebih giat dalam menjalankan kinerja guru yang meliputi merencanakan, melaksanakan, dan mengevaluasi.

3. Iklim yang Kondusif Pengolahan kelas yang baik, mampu dalam pengaturan fasilitas dan sarana prasarana yang baik, serta hubungan antara guru, siswa, karyawan, dan kepala sekolah yang dapat membuat suasana sekolah menyenangkan. Hal ini dapat membuat perasaan senang dan semangat bagi guru yang sedang melaksanakan tugasnya.'

Kepala sekolah sangat menentukan keberhasilan suatu sekolah. Dengan demikian pengertian kepala sekolah dapat didefinisikan sebagai seorang tenaga fungsional guru yang diberi tugas untuk memimpin suatu sekolah dimana diselenggarakannya proses belajar mengajar, atau tempat dimana terjadi interaksi antara guru yang memberi pelajaran dan murid yang menerima pelajaran (Wahjosumidjo, 2011:81-82). Peran kepala sekolah yaitu sebagai Edukator, Manajer, Administrator, Supervisor, Leader, Inovator, Motivator yang disingkat menjadi EMASLIM. Namun sesuai dengan permasalahan yang ada dilapangan maka lebih difokuskan pada kepemimpinan dan motivasi kepala sekolah.

\section{Rumusan Masalah.}

Berdasarkan latar belakang akan di rumuskan masalah yang akan di bahas pada artikel literature review agar lebih focus pada kajian pustaka dan hasil serta pembahasan nanti, yaitu: 
1. Apakah pengaruh lingkungan internal terhadap kinerja guru dimasa pandemic covid-19?

2. Apakah pengaruh lingkungan eksternal terhadap kinerja guru di masa pandemic covid-19?

3. Bagaimana kinerja guru di masa pandemic covid-19?

\section{KAJIAN TEORI}

\section{Kinerja Karyawan}

Colquitt et al, (2011) menyatakan bahwa kinerja adalah nilai serangkaian perilaku pekerja yang memberikan kontribusi, baik secara positif maupun negatif, ada penyelesaian tujuan organisasi. Pendapat lain menyatakan bahwa kinerja adalah hasil dari pekerjaan yang berkaitan dengan tujuan organisasi seperti kualitas, efisiensi dan kinerja lain dari efektivitas (Gibson, et al, 2012). Rogelberg (2007), telah menetapkan kinerja kegiatan yang biasanya merupakan bagian dari pekerjaan dan aktivitas individu dan harus melakukannya.

Menurut Sinambela (2016) kinerja pegawai adalah kemampuan pegawai dalam melakukan sesuatu keahlian tertentu. Kinerja pegawai sangatlah perlu, sebab dengan kinerja ini akan diketahui seberapa jauh kemampuan mereka dalam melaksanakan tugas yang dibebankan kepadanya. Mangkunegara (2011) kinerja merupakan hasil kerja secara kualitas dan kuantitas yang dicapai oleh seorang karyawan dalam melaksanakan tugasnya sesuai dengan tanggung jawab yang diberikan kepadanya. Wibowo (2016) kinerja adalah tentang melakukan pekerjaan dan hasil yang dicapai dari pekerjaan tersebut. Kinerja adalah tentang apa yang dikerjakan dan bagaimana cara mengerjakannya.

Secara teori banyak faktor yang dapat mempengaruhi kinerja, menurut Mangkunegara (2011) menyatakan bahwa faktor-faktor yang dapat mempengaruhi kinerja adalah:

1. Faktor kemampuan (ability. Secara psikologis, kemampuan (ability) pegawai terdiri dari kemampuan potensi (IQ) dan kemampuan reality (knowledge + skill). Artinya pegawai yang memiliki IQ di atas rata-rata (IQ 110-120) dengan pendidikan yang memadai untuk jabatannya dan terampil dalam mengerjakan pekerjaan sehari-hari, maka ia akan lebih mudah mencapai kinerja yang diharapkan. Oleh karena itu, pegawai perlu ditempatkan pada pekerjaan yang sesuai dengan keahliannya.

2. Faktor motivasi. Motivasi terbentuk dari sikap (attitude) seseorang pegawai dalam menghadapi situasi (situation) kerja. Motivasi merupakan kondisi yang menggerakkan diri pegawai yang terarah untuk mencapai tujuan organisasi (tujuan kerja). Sikap mental 
merupakan kondisi mental yang mendorong diri pegawai untuk berusaha mencapai prestasi kerja secara maksimal. Sikap mental pegawai harus sikap mental yang secara psikofisik (siap secara mental, fisik, tujuan,dan situasi), artinya seorang pegawai harus siap secara mental, mampu secara fisik, memahami secara fisik, memahami tujuan utama dari target kerja yang akan dicapai, mampu memanfaatkan, dan menciptakan situasi kerja.

Sedangkan menurut Wirawan (2009) faktor-faktor yang mempengaruhi kinerja sumber daya manusia meliputi:

1. Faktor internal pegawai, yaitu faktor-faktor dari dalam diri pegawai yang merupakan faktor bawaan dari lahir dan faktor yang diperoleh ketika ia berkembang. Faktor-faktor bawaan, misalnya bakat, sifat pribadi, serta keadaan fisik dan kejiwaan. Sementara itu, faktor yang diperoleh, misalnya seperti pengetahuan, ketrampilan, etos kerja, pengalaman kerja, dan motivasi kerja.

2. Faktor lingkungan internal organisasi. Dalam melaksanakan tugasnya, pegawai memerlukan dukungan organisasi tempat ia bekerja. Dukungan tersebut sangat mempengaruhi tinggi rendahkan kinerja pegawai. Faktor internal organisasi antara lain teknologi robot, sistem kompensasi, iklim kerja, strategi organisasi, dukungan sumber daya yang diperlukan untuk melaksanakan pekerjaan, serta sistem manajemen dan kompensasi

3. Faktor lingkungan eksternal organisasi. Faktor-faktor lingkungan eksternal organisasi adalah keadaan, kejadian, atau situasi yang terjadi di lingkungan ekternal organisasi, misalnya krisis ekonomi.

Menurut Amstrong dan Baron (2000) secara lengkap menjelaskan bahwa empat faktor yang mempengaruhi kinerja yaitu: 1) faktor personal, meliputi ketrampilan individual, kompetensi, motivasi, dan komitmen, 2) faktor kepemimpinan, yaitu kualitas dari pemberian motivasi, bimbingan dan dorongan yang diberikan oleh pimpinan, 3) faktor sistem pekerjaan dan fasilitas yang diberikan oleh organisasi, dan 4) faktor situasional, meliputi perubahan dan penekanan dari factor internal dan eksternal.

Berdasarkan teori-teori yang telah dikemukan tersebut diatas, akhirnya penulis menyimpulkan bahwa faktor-faktor yang mempengaruhi kinerja individu dalam organisasi dapat bersumber dari lingkungan (termasuk organisasi) maupun faktor-faktor yang berasal dari dalam 
diri pegawai sendiri. Faktor lingkungan yakni faktor-faktor yang berhubungan dengan organisasi, seperti dukungan kepemimpinan, lingkungan kerja. Perceived organizational support, kompensasi, komunikasi, budaya organisasi, penilaian prestasi kerja dan lain-lain sebagainya. Sedangkan faktor yang berasal dari pegawai itu sendiri (individu) yakni yang berhubungan dengan watak, kelakuan dan kualifikasi pribadi dari pegawai yang diimplementasikan dalam bentuk kepuasan kerja, motivasi, komitmen organisasi, loyalitas, disiplin kerja, dan lain sebagainya. Adapun faktor-faktor yang mempengaruhi kinerja karyawan di gambarkan sebagai berikut:

\begin{tabular}{|l|l|l|}
\hline \multicolumn{1}{|c|}{ Faktor Lingkungan } \\
1. Kepemimpinan & \multicolumn{1}{|c|}{ Faktor Individu } \\
2. Lingkungan Kerja & 1. Kepuasan Kerja \\
3. Budaya Organisasi & 2. Motivasi \\
4. Penilaian Prestasi Kerja & 3. Komitmen Organisasi \\
5.Perceived organizational support & 4. Loyalitas \\
6. Kompensasi & 5. Disiplin Kerja \\
7. Komunikasi & 6. Dan lain-lain. \\
8. Dan lain-lain. & \\
\end{tabular}

\section{Gambar 1: Faktor-faktor Yang Mempengaruhi Kinerja}

Menurut Mitchel dalam Sedarmayanti (2013) kinerja karyawan dapat di ukur melalui: 1) Quality of work (Kualitas hasil kerja); 2) Promptness (Ketepatan waktu); 3) Initiative (Prakarsa dalam menyelesaikan tugas); 4) Capability (Kemampuan menyelesaikan tugas); dan 5) Communication (Kemampuan menjalin kerjasama dengan pihak lain).

Selanjutnya Gomes (2013), menyatakan untuk menilai kinerja dapat diukur melalui beberapa indikator sebagai berikut: 1) Quantity of work yaitu jumlah kerja yang dilakukan dalam suatu periode waktu yang telah ditentukan; 2) Quality of work yaitu kualitas kerja yang dicapai berdasarkan syarat-syarat kesesuain dan kesiapannya; 3) Job knowledge yaitu luasnya pengetahuan mengenai pekerjaan dan keterampilan; 4) Creativiness yaitu keaslian gagasan yang dimunculkan dan tindakan keterampilan; 5) Cooperation yaitu kesediaan untuk bekerjasama dengan orang lain; 6) Dependability yaitu kesadaran dan dapat dipercayakan dalam hal kehadiran dan penyelesaian kerja; 7) Initiative yaitu semangat untuk menyelesaikan tugastugas baru dalam memperbesar tangung jawabnya; dan 8) Personal quality yaitu menyangkut kepribadian, kepemimpinan, keramah tamahan, dan integritas pribadi. 
Kemudian menurut Werther dan Davis (2010) penilaian kinerja karyawan dalam suatu organisasi dapat di ukur melalui indicator sebagai berikut:

a) Performance improvement yaitu memungkinkan pegawai dan manajer untuk mengambil tindakan yang berhubungan dengan peningkatan kinerja.

b) Compensation adjustment yaitu membantu para pengambil keputusan untuk menentukan siapa saja yang berhak menerima kenaikan gaji atau sebaliknya.

c) Placement decision yaitu menentukan promosi, transfer, dan demotion.

d) Training and development needs yaitu mengevaluasi kebutuhan pengembangan bagi pegawai agar kinerja mereka lebih optimal.

e) Carrer planning and development yaitu memandu untuk menentukan jenis karir dan potensi yang dapat dicapai.

f) Staffing process deficiencies yaitu mempengaruhi prosedur perekrutan pegawai.

g) Informational inaccuracies and job-design errors yaitu membantu menjelaskan apa saja kesalahan yang telah terjadi dalam manajemen sumber daya manusia terutama di bidang informasi job-analysis, job-design, dan sistem informasi manajemen sumber daya manusia.

h) Equal employment opportunity yaitu menunjukkan bahwa placement decision tidak diskriminatif.

i) External challenges. Kadang-kadang kinerja pegawai dipengaruhi oleh faktor eksternal seperti keluarga, keuangan pribadi, kesehatan, dan lain-lainnya. Biasanya faktor ini tidak terlalu kelihatan, namun dengan melakukan penilaian kinerja, faktor-faktor eksternal ini akan kelihatan sehingga membantu departemen sumber daya manusia untuk memberikan bantuan bagi peningkatan kinerja pegawai.

j) Feedback. Memberikan umpan balik bagi urusan kepegawaian maupun bagi pegawai.

Berdasarkan uraian di atas dapat disintesiskan bahwa kinerja karyawan adalah adalah keseluruhan hasil kerja yang dilakukannya dan taraf kesuksesan yang dicapai oleh pegawai dalam bidang pekerjaannya yang secara langsung dapat tercermin dari output yang dihasilkan baik yang berupa jumlah maupun kualitasnya, menurut kriteria yang diberlakukan untuk pekerjaan tersebut. Yang dapat diukur melalui beberapa indikator sebagai berikut: 1) Quality of work; 2) Quantity of work; 3) Job knowledge; 4) Attitude; 5) Communication; dan 6) Initiative. 
Kinerja Karyawan sudah banyak di teliti oleh peneliti sebelumnya diantaranya adalah: (Ali et al., 2016), (Prihartono \& Ali, 2020), (Harini et al., 2020), (Riyanto, Pratomo, et al., 2017), (Brata, Husani, Hapzi, 2017), (Agussalim, Kristin, et al., 2016), (Desfiandi et al., 2017), (Sulaeman et al., 2019), (Djojo \& Ali, 2012), (Riyanto, Sutrisno, et al., 2017), (Prayetno \& Ali, 2017), (Ridwan et al., 2020), (Djoko Setyo Widodo, P. Eddy Sanusi Silitonga, 2017), (Agussalim, Ayu Rezkiana Putri, et al., 2016),

\section{METODE PENULISAN}

Penelitian ini menggunakan metode deskriptif kualitatif, hal ini dikarenakan tujuan penelitian ini adalah untuk memperoleh jawaban dan makna yang mendalam mengenai beberapa faktor penunjang dan penghambat guru dengan sistem pembelajaran daring. Pengumpulan data dan informasi dilakukan melalui kontak langsung dengan subjek penelitian dengan cara wawancara, observasi dan telaah dokumentasi. Peneliti mewawancarai dan mengamati langsung faktor-faktor penunjang dan penghambat guru dalam mengikuti pembelajaran daring, selanjutnya peneliti menelaah dokumen-dokumen pelaksanaan secara daring untuk mendeskripsikan keadaan guru mengikuti pembelajara secara daring.

Analisis data dilakukan bersamaan dengan pengumpulan data di lapangan dengan cara mereduksi data, penyajian data dan penarikan kesimpulan serta melakukan verifikasi data dengan triangulasi data (Miles \& Huberman, 1992). Fokus kajian ini adalah pada dua hal, yaitu faktorFaktor pendukung ditemukan sebanyak dua faktor dan faktor penghambat ditemukan sebanyak tiga faktor.

\section{KESIMPULAN DAN SARAN}

Hasil penelitian menunjukkan dua faktor penunjang guru dalam pembelajaran daring pada program pendidikan. Pertama, dukungan teman sejawat dalam kelompok pembelajaran daring dan faktor dukungan keluarga. Faktor kedua adalah motivasi.

Faktor motivasi terbagi kepada dua hal yaitu; motivasi akan mendapat pengakuan di sekolah sebagai bentuk aktualisasi diri dan motivasi akan memberikan sumbangan pada akreditasi sekolah. Sedangkan tiga faktor penghambat pertama adalah ketidakmampuan dalam penguasaan teknologi informasi dan telekomunikasi, kedua, jaringan internet, ketiga waktu pelaksanaan dan komitmen dengan instruktur.

Diperlukan pelatihan secara khusus dan kontinyu terutama di daerah terpencil. Kemudian penggunaan IT dijadikan pembiasaan agar berdampak pada kemandirian dan kreativitas serta 
inovasi guru dalam mengoperasikan sendiri laptop untuk programprogram sederhana tanpa bergantung pada orang lain serta media sosial lain yang bersifat online untuk mengembangkan kompetensi profesionalnya. Kendala yang dialami guru hendaknya dijadikan bahan evaluasi oleh kepala sekolah, dinas serta stakeholder terkait agar tujuan pendidikan dapat dicapai dengan optimal.

\section{DAFTAR PUSTAKA}

Agussalim, M., Ndraha, H. E. M., \& Ali, H. (2020). The implementation quality of corporate governance with corporate values: Earning quality, investment opportunity set, and ownership concentration analysis. Talent Development and Excellence.

Anwar, K., Muspawi, M., Sakdiyah, S. I., \& Ali, H. (2020). The effect of principal's leadership style on teachers' discipline. Talent Development and Excellence.

Andri Yandi1 , Ridho Rafqi Ilhamalimy2 Diterminasi Kinerja Karyawan: Perceived Oganization Suport (POS), Komunikasi, dan Gaya Kepemimpinan(Suatu Kajian Studi Literatur Manajemen Sumberdaya Manusia).

Chauhan, R., Ali, H., \& Munawar, N. A. (2019). BUILDING PERFORMANCE SERVICE THROUGH TRANSFORMATIONAL LEADERSHIP ANALYSIS, WORK STRESS AND WORK MOTIVATION (EMPIRICAL CASE STUDY IN STATIONERY DISTRIBUTOR COMPANIES). Dinasti International Journal of Education Management And Social Science. https://doi.org/10.31933/dijemss.v1i1.42

Ekiman wenda.2015.Analisis Pengaruh Faktor Internal dan Faktor Eksternal Terhadap Kinerja

Guru SMP Negeri 4 Mimika Kabupaten Timika.Universitas Terbuka Jakarta.

Elmi, F., Setyadi, A., Regiana, L., \& Ali, H. (2016). Effect of leadership style, organizational culture and emotional intelligence to learning organization: On the Human Resources Development Agency of Law and Human Rights, Ministry of Law and Human Rights. International Journal of Economic Research.

https://eprints.uny.ac.id/17662/2/2\%20ISI\%20.pdf

http://repository.uin-suska.ac.id/6669/2/BAB\%20I.pdf

Jurnal SDM Guru Covid 4.pdf

https://ibnurus.blogspot.com/2017/06/kinerja-guru-dan-faktor-faktor-yang.html

https://bdkbanjarmasin.kemenag.go.id/berita/kinerja-dan-kompetensi-guru

https://eprints.uny.ac.id/7965/3/bab\%202\%20-10504247012.pdf

https://ainamulyana.blogspot.com/2012/02/kinerja-guru.html

epository.uin-suska.ac.id/6181/3/BAB\%20II.pdf 